\title{
Elastic Lateral-Torsional Buckling Load on Circular Fixed Channels Arches Under Transverse Point Load
}

\author{
Emmanuel-Peters Teke Tebo ${ }^{1, *}$ \\ Leonard Masu \\ Patrick Nziu ${ }^{3}$ \\ ORCID: 0000-0003-4926-8828 \\ ORCID: 0000-0002-8544-6321 \\ ORCID: 0000-0002-5899-0700 \\ ${ }^{1,2,3}$ Department of mechanical engineering, Vaal University of Technology, Andries Potgieter Blvd, \\ Vanderbijlpark, 1900, Gauteng, South Africa.
}

\begin{abstract}
This paper investigated the elastic Lateral-Torsional Buckling (LTB) loads of circular fixed ends arches of 6061-T6 aluminium alloy channels subjected to transverse point load at the shear center. Finite Element Analysis (FEA) software package known as Abaqus was used to investigate a total of 55 models from three different channel profiles. Out of these arches, 33 arches were developed at a constant span length. While, the other 22 arches were modeled at constant slender ratio using 11 distinct included angles. The prebuckling FEA results were compared with those generated by existing analytical solutions for validation. The results generated by these two aforementioned methods showed good agreement. Further analyses of FEA results established that the crosssection area, slender ratio, and included angles of the arches had significant impact on both the LTB loads and their behaviours as in the reviewed literature. Unlike in the prebuckling analyses where the load magnitude had negliglible effects, it was revealed that the magnitude of the overall buckling load depended on the torsion constant, for arches with constant span length. For included angles with high resistance to LTB, the following order of suitability was established for arches developed at constant span length $50^{\circ} \leq 2 \alpha \leq 90^{\circ}$, $2 \alpha<50^{\circ}$ and $90^{\circ}<2 \alpha \leq 180^{\circ}$. Whereas, the order of preference for arches developed at constant slender ratio for the same included angles was $90^{\circ}<2 \alpha \leq 180^{\circ}, 50^{\circ} \leq 2 \alpha \leq$ $90^{\circ}$ and $2 \alpha<50^{\circ}$.
\end{abstract}

Keyword: circular fixed arches, elastic lateral-torsional buckling, shear center, concentrated load, prebuckling

\section{INTRODUCTION}

The application of thin-walled, open sections as the loadbearing skeleton in structures is widespread (La Poutré 2005). Some of these thin-walled open sections are used as arches, which can be pin supported or fixed (Spoorenberg et al. 2012; Tebo et al. 2020). These arches may experience common buckling stability problems such as the Lateral-Torsional Buckling (LTB), which is a common occurrence in arches subjected to transverse point load (Wesley 2017). For LTB to occur, the compression flange edge has to yield, causing inplane bending on members' strong axis to change to lateral displacement and twisting (Ozbasaran, Aydin, \& Dogan 2015; Bajer, Barnat, \& Pijak 2017).

Several studies have reported the effects of LTB on arches with fixed supports (Pi and Bradford 2012). However, studies on the elastic LTB on fixed circular arches subjected to concentrated loads are still scarce. This scarcity is due to the complex nature that exists with the analysis of such arches. This complexity comes as a result of the non-uniform axial compressive force and bending moment having complicated distribution pattern caused by the applied concentrated load (Liu et al., 2017). For example, Figure 1 shows the reactions developed on a freestanding circular fixed arch under transverse point load,

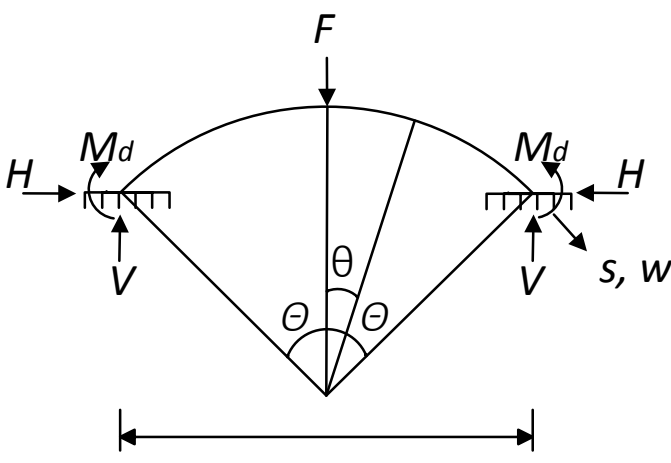

(i) Fixed arch

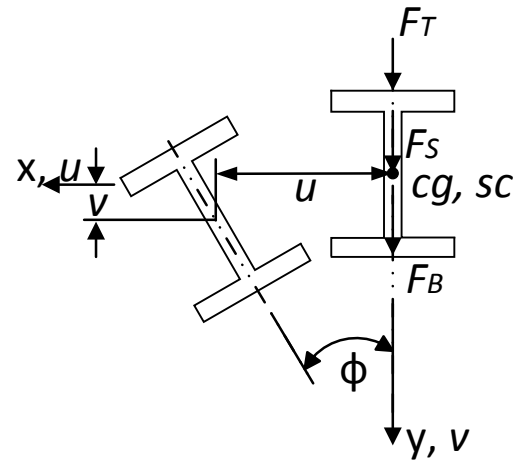

(ii) Lateral-torsional buckling

Figure 1: Fixed arch reactions under concentrated transverse point load (Redrawn from Tebo et al. 2020)

\footnotetext{
${ }^{*}$ Corresponding Author.
} 
where $H$ and $V$ are the horizontal and vertical reactions, $M_{d}$ is the end moment reaction, $L$ is the span arch length, $w, v, u$ and $s$ are the tangential, radial, lateral and axial displacements of the centroid of the cross-section, $\phi$ twist rotation of the crosssection, $2 \Theta$ is the included angle, $\theta$ angular position of the bending moment, $c g$ and $s c$ are the center of gravity and shear center respectively, $F_{T}, F_{S}, F_{B}$ represent the applied point load at different heights that is the top flange, shear center, and bottom flange respectively, $x$ and $y$ are the coordinates of a point load in the principal axis of the cross-section.

Nonetheless, some researchers have used numerical, experimental, and analytical methods to conduct intensive studies on these arches. From reviewed studies, the study by Pi and Trahair (1996) proposed a 3D nonlinear finite element model that included the Wagner and post-buckling effects for analyzing elastic arches of double symmetric sections with fixed supports. The solution reported by these authors compared favourably to those generated by Yang, Kuo, and Cherng (1989) work that had assumed trivial prebuckling state of stress. A subsequent study by Pi, Bradford, and Tong (2010) found that the prebuckling state of stress had significant effects on the LTB load for both in-plane fixed arches and out-of-plane pin-ended arches subjected to concentrated load. The authors further developed analytical solutions to predict LTB load that compared favourably with solutions generated by other studies by Pi et al. (2005) and Pi and Trahair (1996). These solutions where based on numerical methods, that is; FEA ANSYS software and an inhouse beam-element code methods, respectively. In another study, Liu et al. (2017a) used similar design arrangement to the work of Pi et al. (2010) to investigate the elastic out-of-plane LTB of fixed circular arches for double symmetric I-section subjected to central concentrated load. Their proposed solutions showed good agreement with other solutions generated by FEA ANSYS software. These findings further reaffirmed the significant influence of the slender ratio and included angle on the LTB load.

Nonetheless, the aforementioned studies focused more on double symmetric I-sections, which are relatively simple to analyze as their center of gravity and shear center coincide. Besides, this is not the case for open thin-walled channels whose center of gravity and shear center do not coincide (Dahmani \& Drizi 2015). Unfortunately, limited design data still exist on these channels, despite being highly rated in performance and having less weight (Kim, Min, \& Su 2000a). However, inadequate data is even more significant for structural aluminium members (Wang et al. 2012). Regardless of numerous benefits associated with the use of aluminium alloys such as lightweight, good durability, recyclability, sustainability, and corrosion resistance that makes the aluminium alloy justifiably described as green metal (Efthymiou, Cöcen \& Ermolli 2010; Tebo et al. 2020).

Hence, the aim of this study was to investigate the elastic LTB load for fixed circular arches of 6061-T6 aluminium alloy channels subjected to a concentrated transverse point load at the shear center. In addition to this, the effects of slender ratios and cross-sections on elastic LTB were also evaluated.

\section{METHODOLOGY}

\subsection{Cases studied}

Aluminium (Al) alloy 6061-T6 was chosen for this case study due to its frequent application in structures (Wang et al., 2012). Three Al channels with part numbers 16831, 16825, and 16045 as specified in the Aluminium Standard Profile Catalog by Hulamin Extrusions, (2015) and that falls within class 1, and 2 categories reported by Mazzolani, (2004) were used in this study. Figure 2 shows the overviews of the cross-section.
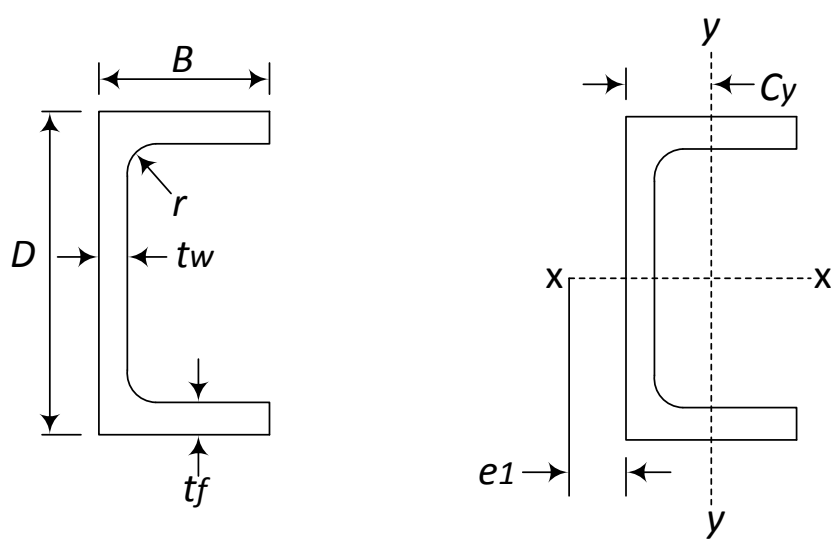

Figure 2: General cross-section of the aluminium alloy channel

Whereby $D$ is the height of the web, $B$ is the flange width, $t_{f}$ is the flange thickness, $t_{w}$ is web thickness, $r$ is the inner radius of the web and flange, $e_{l}$ is the position of the shear center, and $C_{y}$ is the position of the center of gravity. Based on the defined parameters in Figure 2, Table 1 outlines the detailed description of the selected channel cross-sections.

Table 1: Detail description of cross-sections studied in accordance with Figure 2 (Hulamin Extrusions, 2015)

\begin{tabular}{|c|c|c|c|}
\hline Cross-section profiles & Profile & Profile & Profile \\
\hline Profile number & $\mathbf{1 6 0 4 5}$ & $\mathbf{1 6 8 2 5}$ & $\mathbf{1 6 8 3 1}$ \\
\hline Cross-section & Class $\mathbf{2}$ & Class $\mathbf{1}$ & Class $\mathbf{1}$ \\
\hline Height of the web $(\mathrm{D})$ in & 25.4 & 25.4 & 38.1 \\
\hline Width of the flange $(B)$ in & 12.7 & 12.7 & 12.7 \\
\hline Web and flange thickness & 1.6 & 3.18 & 3.18 \\
\hline$r(\mathrm{~mm})$ & 0.64 & 0.4 & 0.3 \\
\hline$e_{1}(\mathrm{~mm})$ & 3.6 & 2.5 & 2 \\
\hline$C_{y}(\mathrm{~mm})$ & 3.8 & 4.3 & 3.7 \\
\hline
\end{tabular}

The channel profiles listed in Table 1 were used to develop freestanding arches models. The models developed from each profile differ from one another with the included angle. Figure 3 shows a schematic representation of the developed arch model investigated in this study. 

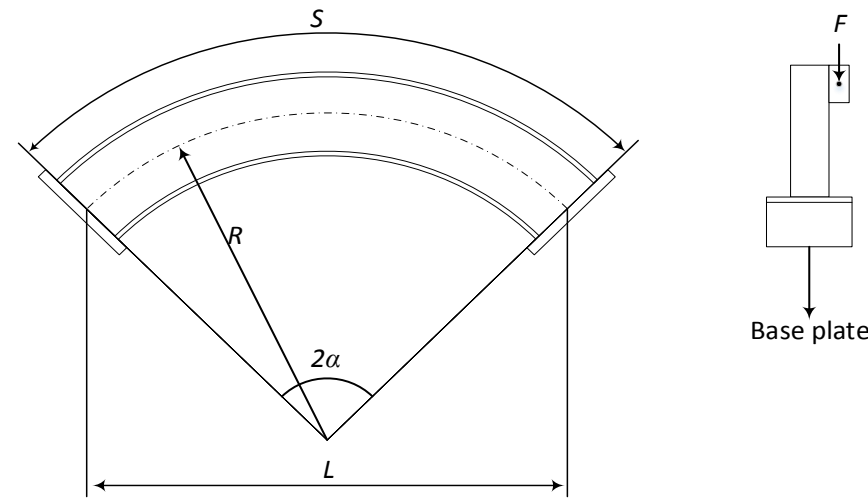

Figure 3: Structural representation of the arch model

Whereby $L$ is the span length, $S$ is the arc length, $R$ is the mean radius, $2 \alpha$ is the included angle, $F$ is the applied point load at the shear center. Based on these parameters, 11 models were developed from each profile using 11 distinct included angles. The included angle was the primary parameter that distinguishes each model from one another, while the constant slender ratios and span length acted as secondary parameters.

Table 2: Structural representation of the different models generated from a profile

\begin{tabular}{|c|c|c|c|c|c|}
\hline \multirow{3}{*}{$\begin{array}{l}\text { Model } \\
\text { Number }\end{array}$} & \multirow{2}{*}{$\begin{array}{l}\text { Group } \\
\text { One }\end{array}$} & \multicolumn{2}{|c|}{ Group Two } & \multirow{2}{*}{\multicolumn{2}{|c|}{$\begin{array}{l}\text { Included angle } \\
\qquad 2 \alpha\end{array}$}} \\
\hline & & $S / r_{x}=60$ & $S / r_{x}=90$ & & \\
\hline & $\begin{array}{l}\text { Span } \\
\text { length } \\
L \\
{[\mathrm{~mm}]}\end{array}$ & $\begin{array}{c}\text { Span } \\
\text { length } L \\
{[\mathrm{~mm}]}\end{array}$ & $\begin{array}{c}\text { Span } \\
\text { length } L \\
{[\mathrm{~mm}]}\end{array}$ & $\begin{array}{l}\text { Angle } \\
\text { in }\left(^{\circ}\right)\end{array}$ & $\begin{array}{l}\text { Arch } \\
\text { group }\end{array}$ \\
\hline 1 & 500 & 549.64778 & 824.47167 & 5 & \multirow{5}{*}{$\begin{array}{l}\text { Shallow } \\
\text { arches }\end{array}$} \\
\hline 2 & 500 & 549.12464 & 823.68695 & 10 & \\
\hline 3 & 500 & 548.25339 & 822.38009 & 15 & \\
\hline 4 & 500 & 547.03505 & 820.55258 & 20 & \\
\hline 5 & 500 & 543.56301 & 815.34452 & 30 & \\
\hline 6 & 500 & 532.54115 & 798.81173 & 50 & \multirow{3}{*}{$\begin{array}{l}\text { Moderate } \\
\text { arches }\end{array}$} \\
\hline 7 & 500 & 516.25965 & 774.38947 & 70 & \\
\hline 8 & 500 & 495.01392 & 742.52088 & 90 & \\
\hline 9 & 500 & 454.69932 & 682.04898 & 120 & \multirow{3}{*}{$\begin{array}{l}\text { Deep } \\
\text { arches }\end{array}$} \\
\hline 10 & 500 & 405.72095 & 608.58143 & 150 & \\
\hline 11 & 500 & 350.0277 & 525.04155 & 180 & \\
\hline
\end{tabular}

A total of 33 models were developed at a constant span length $L=500 \mathrm{~mm}$, with 11 models from each profile. Also, a total of 22 models were developed from profile 16825 at constant slender ratios $S / r_{x}=60$ and 90 (where $r_{x}$ is the radius of gyration about the major axis). These models add up to a total of 55 models investigated in this study. The effects of the slender ratio were investigated using profile 16825 as the profile had been identified to have an approximate mean crosssectional property, amongst the three studied channel profiles. Table 2 summarizes the parameters used to develop the different models investigated in this study.

\subsection{Numerical method}

The numerical technique used in this study is the Finite Element Analysis (FEA) method. This FEA method was selected because of its flexibility to perform elastic and inelastic analyses. Thus, increasing the degree of accuracy in cases where comparison between elastic and inelastic results is required. Also, for years, the FEA method has acted as a more convenient and reliable tool to investigate the influence of various factors such as included angles, cross-section, and inplane slender ratios on the LTB of arches (Liu et al. 2017a).

\subsubsection{Modelling}

3D FEA software package Abaqus was used to developed 55 arch models categorized in two groups. The first group consisted of 33 arch models with 11 arch models from each profile, developed at a constant span length $=500 \mathrm{~mm}$. Whereas, the second category comprised of 22 arch models formed from profile 16825 at constant slender ratios $S / r_{x}=60$ and 90 (where $S$ is the length of the arc and $r_{x}$ is the radius of gyration about the major axis).

\subsubsection{Part creation}

Among other important built-in modeling options in Abaqus, a 3D space, deformable type, with the basic features of shell shape and sweep style, were used to develop the arch models being investigated. Figure 4 shows the sample of the an arch model created.

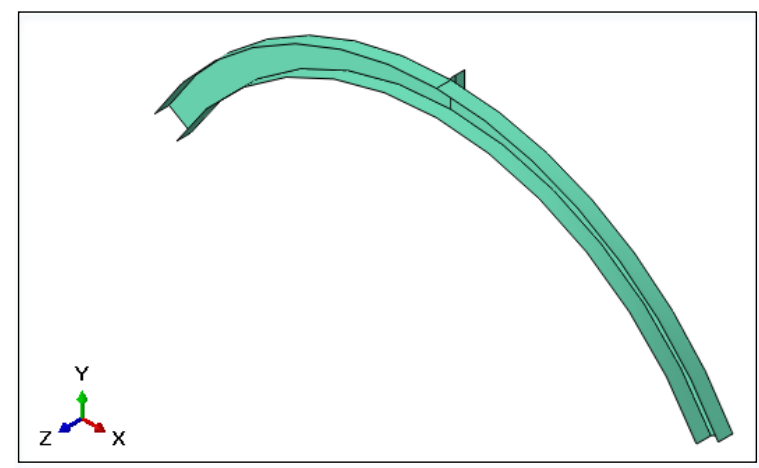

Figure 4: Sample part model

\subsubsection{Material properties}

The young modulus $E=68.9 \mathrm{GPa}$, and Poisson's ratio of 0.33 for 6061-T6 Al alloy as specified in the Aerospace Specification Metals Inc, (2012) material catalogue were used to describe the elastic properties of the material. 


\subsubsection{Load and boundary conditions}

The state of encastre boundary was chosen because it guarantees no displacement and rotation in the $\mathrm{x}, \mathrm{y}$, and $\mathrm{z}$ directions, thereby providing restriction of in-plane and out-ofplane movement at the supports. A point load acting downward in the y-direction was applied at the shear centre through an additional welded plate that is twice the thickness of the profile to avoid any deformation on the plate. The load was able to move in the $\mathrm{x}$ and $\mathrm{z}$-directions depending on the rate of deformation as there was no added constraint on the load. In practice this point load can be applied using masses as a tiedown transverse load.

\subsubsection{Meshing of the model}

The arches were modeled using shell element S4R with linear geometric order. The SR4 is a three-dimensional, four-node, quadrilateral, stress/displacement doubly curved generalpurpose shell element with six degrees of freedom at all nodes. This type of element is known to provide reliable results for thin-walled members and is ideal for research work involving finite membrane strains and large rotations (Valeš \& Stan, 2017). For the mesh sizes, a $2 \mathrm{~mm}$ mesh size that gave six elements on the flange and eight elements on the web for profile 16825 and 13 elements on the web of profile 16831 was selected. This selection of the mesh size was established from a convergence study that took into consideration the percentage difference between the elements as well as the processing running time. Figure 5 shows a schematic representation of the developed FE model in Abaqus.

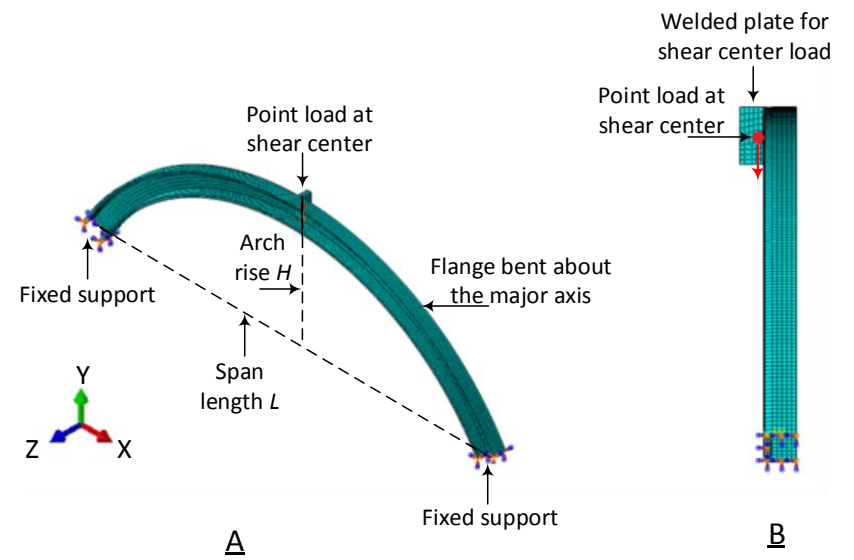

Figure 5: Practical representation of the arch model $(A)$ isometric view (B) side view B

\subsubsection{Solving phase}

The two major elastic analyses carried out were the linear elastic analysis (LEA), and linear buckling analysis (LBA). The LEA was solved with the default static general procedure to determine the axial compressive forces and bending moment prior to buckling. The point of interest for the prebuckling was at the crown where the maximum axial compressive and bending actions are expected to occur as reported in other studies studies by Pi and Trahair (2000), Pi and Bradford (2003), and Pi et al. (2010). On the other hand, the LBA was used to determine the elastic LTB load, (also referred to as the eigenvalue or elastic critical resistance) and buckling behavior, (also referred to as the eigenmode). The elastic LTB load $F_{c r}$ was obtained using equation (1) as reported by (Spoorenberg 2011).

$$
F_{c r}=\beta_{c r} . F
$$

Where $F$ is the unit load in Newton $(N)$ applied at the shear center as shown in Figure 5 and $\beta_{c r}$ is the elastic critical resistance of buckling obtained from the FEA.

\subsection{Validation of the finite element model}

The FE models developed using Abaqus were validated using the existing analytical solutions proposed by Pi and Bradford, (2003) and Liu et al., (2017a) studies. Since these existing analytical solutions were derived for double symmetric Isections, as such, it was advisable to compute the analytical solutions to a similar FE model. Therefore, the same methodology, load, and boundary conditions used for the channel profiles arch models were applied to the I-section.

The cross-section dimensional properties of the 6061-T6 Al Isection used for the FE model verification are given as follows; web width $D=15.82 \mathrm{~mm}$, flange width $B=7.04 \mathrm{~mm}$, flange thickness $t_{f}=1.42 \mathrm{~mm}$, web thickness $t_{w}=1.38 \mathrm{~mm}$, mean radius of the arch $R=500 \mathrm{~mm}$, point of the applied load from shear center $y_{p}=-7.91 \mathrm{~mm}$ and the load applied $F=1 \mathrm{~N}$.

A total of 11 arches modelled at exact included angles given in Table 2 were used for the validation.

Similar to the investigated models in this study, the point of interest was at the crown. The axial compressive force and central bending moments obtained from both the FEA and analytical solutions were then compared graphically. The results were presented in the dimensionless form. That is, the dimensionless axial compression force $\left(N_{C} / F\right)$, and dimensionless bending moment $\left(4 M_{C} / F L\right)$.

\section{RESULTS AND DISCUSSION}

In this section, the results generated by various methods described in the preceding section are presented and discussed under the following three subheadings;

\subsection{Preliminary validation of results}

The results obtained from the analytical and FEA are compared using graphs with the $N_{C} / F L$, and $4 M_{C} / F L$ being presented on separate graphs. The $N_{C} / F L$, and $4 M_{C} / F L$ parameters are plotted as the ordinates, while the included angles $(2 \alpha)$ as the abscissa. Figure 6 presents the comparison between the elastic analytical and FEA prebuckling results. 


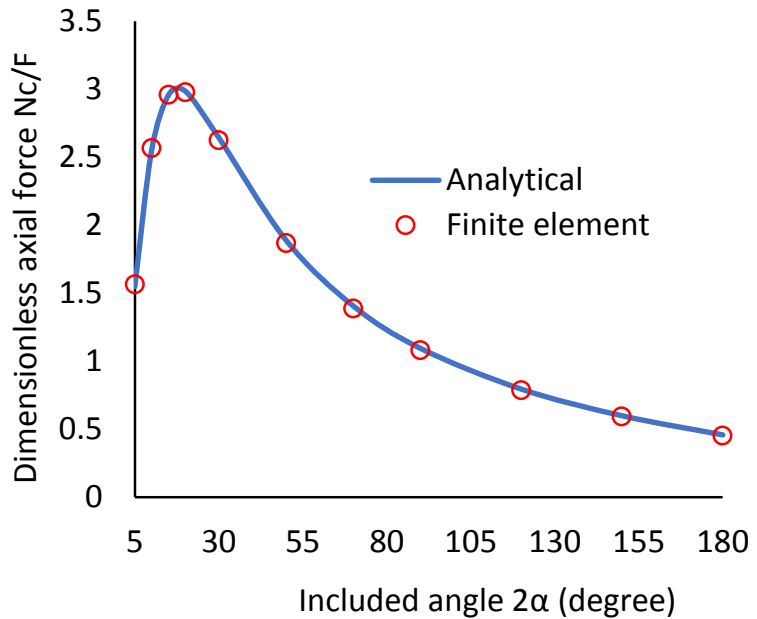

(A)

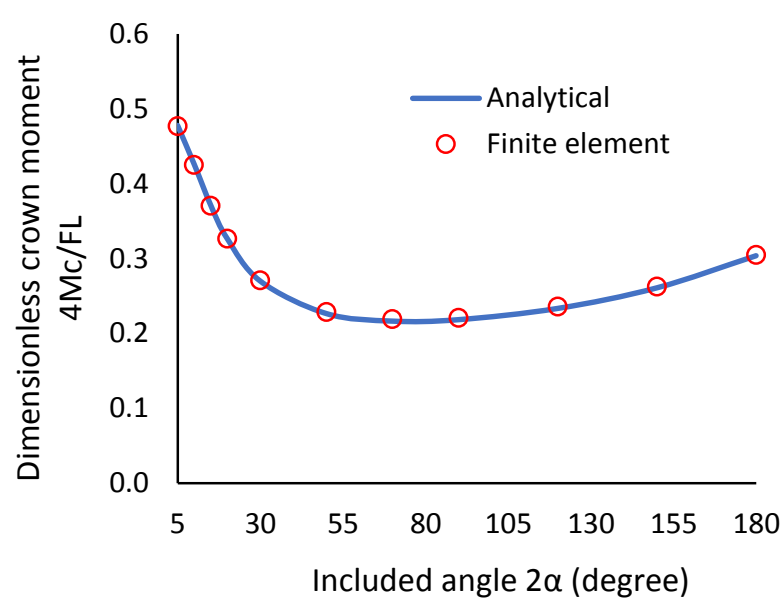

(B)

Figure 6: Comparison of the finite element and theoretical dimensionless (A) axial compressive force and (B) bending moment at the crown at various included angles

As observed in Figure 6, the FEA and analytical solutions show incredibly good agreements. The agreement is evidence that the FE modeling technique used to model the investigated freestanding circular fixed arches of the channel sections was done correctly.

\subsection{Presentation and discussion of prebuckling results}

This section presents the axial compressive force and central bending moment results obtained from profiles 16045, 16825 and 16831 at constant span length $L=500 \mathrm{~mm}$ and profile 16825 at slender ratios $S / r_{x}=60$ and 90 at included angles $2 \alpha$. It is important to note that the slender ratios for arches developed at $L=500 \mathrm{~mm}$ change with included angle. Thus, such arches were used in this study to evaluate the effect of the change in web-flange thickness, and web height on the prebuckling behaviour and buckling load. The arches developed at $S / r_{x}=60$ and 90 maintained the same slender ratio at every included angle and were used to evaluate the effects of the increase in slender ratio on the prebuckling behaviour and buckling load.

\subsubsection{Axial compressive force}

The axially compressive forces obtained from arches developed at the constant span length $L=500 \mathrm{~mm}$ are reported separately from those developed at the constant slender ratios $S / r_{x}=60$, and 90.

\subsubsection{Axial compressive forces of arches developed at constant span length}

Figure 7 presents the variation of the dimensionless axial compressive force $N c / F$ against the included angles $2 \alpha$ for arches developed at constant span length $L=500 \mathrm{~mm}$.

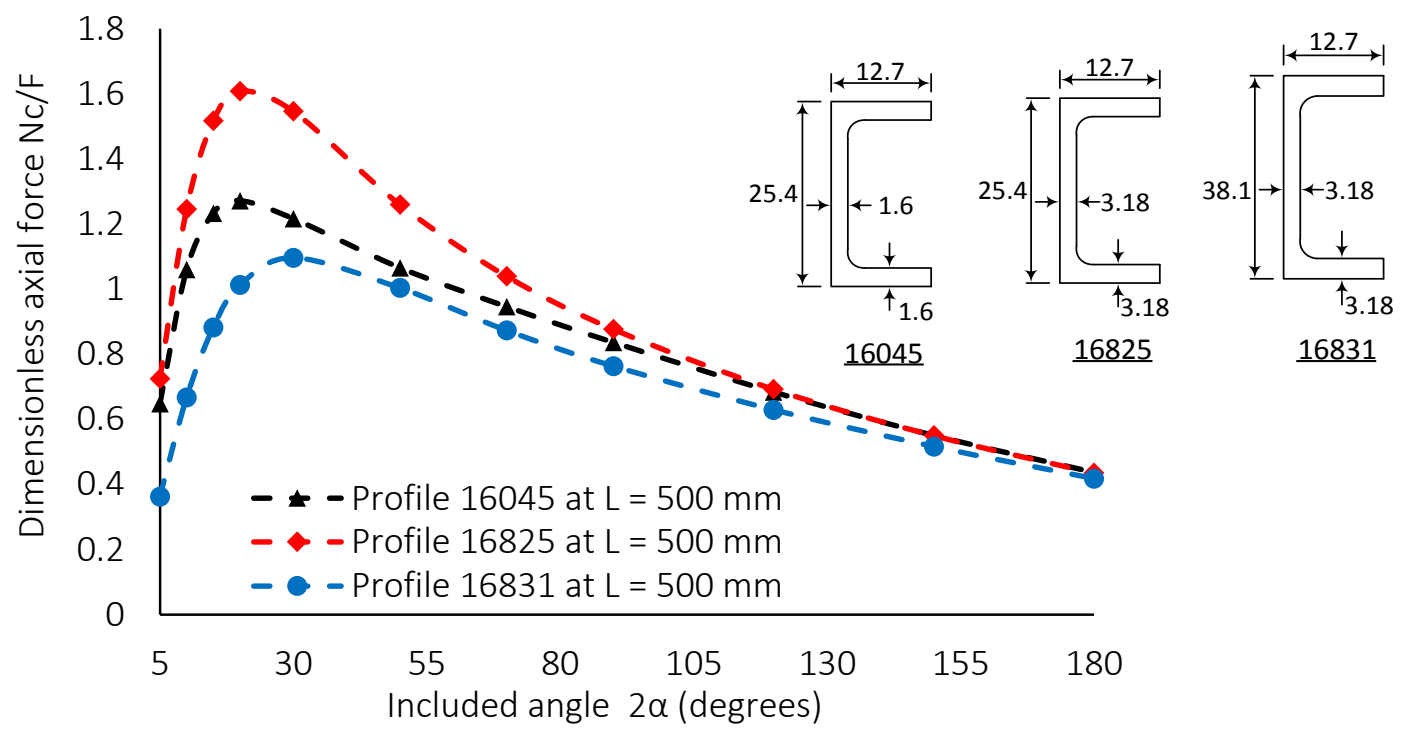

Figure 7: Cross-sections variations of the axial compressive force with included angles 
As illustrated in Figure 7, the $N_{C} / F$ values for all the crosssections rapidly increase to a maximum at $2 \alpha<30^{\circ}$, and then decreased with an increase in included angle, when $2 \alpha>30^{\circ}$. Also, it was noted that profile 16825 has an overall high magnitude of the axial force. The overall high magnitude axial force generated by the profile 16825 was due to the large distance between the profile centroid position and its shear centre. That is as compared to the distance between the centroid position and shear centre for profile 16045 and 16832, respectively, as outlined in Hulamin Extrusions, (2015) catalogue.
Based on reported studies, an arch developed at a constant slender ratio with a high elastic axial compressive force should have the least LTB load (Pi and Bradford, 2003). However, the same remark cannot be made for arches developed at constant span length due to other factors such as torsion constant and bending moment that may have significant influence on the LTB load. That said, the various maximum and minimum $N_{C} / F$ values in Figure 7 at relative included angles are summarized in Table 3. It should be noted that profile 16825 was used as the point of reference for comparison due to its mean dimensional property.

Table 3: Maximum and minimum $N_{C} / F$ values at the respective included angles and percentage differences for arches developed at constant span length

\begin{tabular}{|c|c|c|c|c|c|c|c|}
\hline \multicolumn{3}{|c|}{$\begin{array}{l}\text { Profile description } \\
\text { (dimensions in mm) }\end{array}$} & \multicolumn{2}{|c|}{$\begin{array}{c}\text { Maximum } \frac{N_{C}}{F} \text { and } \\
\text { corresponding included } \\
\text { angle } 2 \alpha\end{array}$} & \multicolumn{2}{|c|}{$\begin{array}{c}\text { Minimum } \frac{N_{C}}{F} \text { and } \\
\text { corresponding included } \\
\text { angle } 2 \alpha\end{array}$} & \multirow{2}{*}{$\begin{array}{c}\text { Maximum } \frac{N_{C}}{F} \text { percentage } \\
\text { difference at } \\
\text { corresponding included } \\
\text { angle } 2 \alpha(\%) \text { Ref. } 16825\end{array}$} \\
\hline Profile & $\begin{array}{l}\text { Web \& flange } \\
\text { thickness }\end{array}$ & Web height & $\frac{N_{C}}{F}$ & $2 \alpha\left(^{\circ}\right)$ & $\frac{N_{C}}{F}$ & $2 \alpha\left(^{\circ}\right)$ & \\
\hline 16825 & 3.18 & 25.4 & 1.608 & 20 & 0.435 & 180 & - \\
\hline 16045 & 1.6 & 25.4 & 1.271 & 20 & 0.437 & 180 & 23.4 \\
\hline 16831 & 3.18 & 38.1 & 1.096 & 30 & 0.362 & 5 & 38.9 \\
\hline
\end{tabular}

From Table 3, it can be seen that profiles 16045 and 16825 attained their maximum $N_{C} / F$ values at $2 \alpha=20^{\circ}$, and minimum at $2 \alpha=180^{\circ}$. While the maximum and minimum $N_{C} / F$ values for profile 16831 were attained at $2 \alpha=30^{\circ}$ and $2 \alpha=5^{\circ}$, respectively. This revealed that for these channel profiles, dimension factors such as the change in web height have an influence on the included angle at which the maximum and minimum axial compressive forces occur. Also, if the cross-sectional thickness is reduced by $50 \%$ that is from profile 16825 to 16045 , the maximum axial compressive force may reduce by up to $23.4 \%$. In the case whereby the web hight is increased by approximately $66.7 \%$ that is from profile 16825 to 16831, the maximum axial compressive force may reduce by up to $38.9 \%$. These significant differences between the $N_{C} / F$ values noticed at included angle $2 \alpha=20^{\circ}$, and $30^{\circ}$ can be associated with the uniformly distributed axial compressive forces along the arch length as reported by Liu et al. (2017a) study.

In summary, the effects of the change in web-flange thickness, and web height influences the magnitude of the axial compressive forces, but not the overall behaviour. Based on studies reported by Pi and Trahair (1996) and Liu et al. (2017a), one should expect a decrease on the LTB loads at $5^{\circ} \leq 2 \alpha \leq$ $50^{\circ}$ due to the high axial compressive forces.

\subsubsection{Axial compressive forces of arches developed at constant slender ratios}

The variation of the dimensionless axial compressive force $N c / F$ against the included angles $2 \alpha$ for arches developed at length $S / r_{x}=60$ and 90 are presented in Figure 8. 


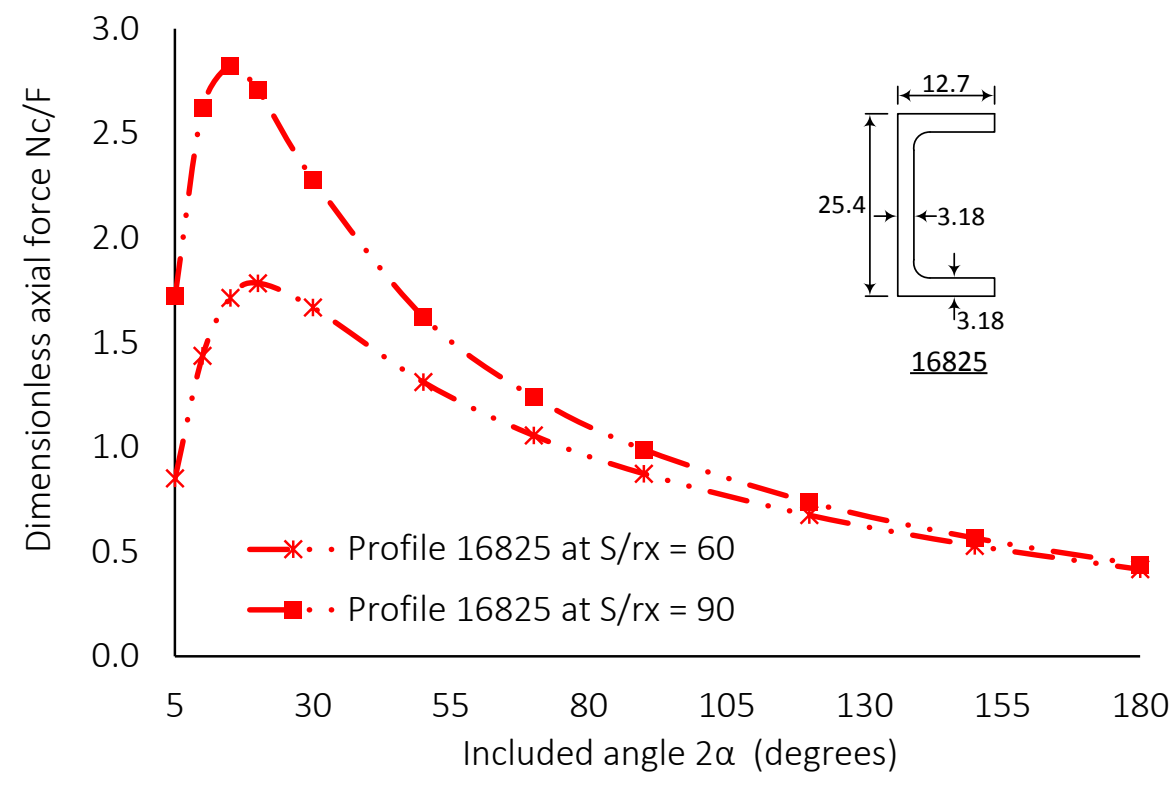

Figure 8: Slender ratios variations of the axial compressive force with included angles

As noted in Figure 8, the $N_{C} / F$ values for both arches first increased to their peak values and then decreased gradually to their minimum values with the increase in the included angles. Also, it can be seen that the overall $N_{C} / F$ magnitudes for arches developed at $S / r_{x}=90$ are higher than those developed at $S / r_{x}=60$. The high $N_{C} / F$ values were attributed to the long arc length developed as compared to the short arc length in arches modelled at $S / r_{x}=60$ (Pi \& Bradford 2003). The close variance observed at $2 \alpha>120^{\circ}$ was due to the profound differences in the span lengths between both slender ratios. That said, one should generally expect arches with an overall high elastic axial compressive forces influenced by their high slender ratios to have an overall low resistance to LTB as reported by Liu et al. (2017a) study. The maximum and minimum $N_{C} / F$ values shown in Figure 8 are summarized in Table 4 . It should be noted that the $S / r_{x}=90$ curve in this case was used as the point of reference due to its overall high $N_{C} / F$ values.

Table 4: Maximum and minimum $N_{C} / F$ values at their respective included angles and percentage difference for arches developed at constant slender ratios 60 and 90

\begin{tabular}{|c|c|c|c|c|c|}
\hline \multirow[t]{2}{*}{$\begin{array}{c}\text { Slender } \\
\text { ratio } S / r_{x}\end{array}$} & \multicolumn{2}{|c|}{$\begin{array}{c}\text { Maximum } \frac{N_{C}}{F} \text { and } \\
\text { corresponding included angle } 2 \alpha\end{array}$} & \multicolumn{2}{|c|}{$\begin{array}{c}\text { Minimum } \frac{N_{C}}{F} \text { and corresponding } \\
\text { included angle } 2 \alpha\end{array}$} & \multirow{2}{*}{$\begin{array}{l}\text { Maximum } \frac{N_{C}}{F} \text { percentage } \\
\text { difference at corresponding } \\
\text { included angle } 2 \alpha(\%), \text { Ref: } \\
\qquad S / r_{x}=90\end{array}$} \\
\hline & $\frac{N_{C}}{F}$ & $2 \alpha\left(^{\circ}\right)$ & $\frac{N_{C}}{F}$ & $2 \alpha\left(^{\circ}\right)$ & \\
\hline 90 & 2.823 & 15 & 0.438 & 180 & \multirow[t]{2}{*}{45.1} \\
\hline 60 & 1.784 & 20 & 0.416 & 180 & \\
\hline
\end{tabular}

From Table 4 , it can be seen that the maximum $N_{C} / F$ values for slender ratios 90 and 60 were attained at $2 \alpha=15^{\circ}$, and $20^{\circ}$, respectively, with a percentage difference of $45.1 \%$. This reveals two things. Firstly, the slender ratio influences the included angle at which the maximum axial compressive force occurs but has an insignificant influence on the included angle of the minimum axial compressive force. Secondly, by decreasing the slender ratio by $66.7 \%$, which was from 90 to 60 , it may decrease the peak axial compressive force by up $45.1 \%$ for the same included angle. Again, this significant difference was attributed to the long arc length, coupled with the effects of the included angles as observed by Pi et al. (2010) work.

That said, it was evident that the change in slender ratio, does influence the magnitude of the axial compressive force, but not the general behaviour. Also, based on the axial compressive force influence on the LTB load for arches developed at constant slender ratio, shallow arches will yield low resistance to LTB. Thus, they are not suitable for application in areas of high LTB. Furthermore, the $N_{C} / F$ values across the included angles portrayed a similar behaviour to those reported by Liu et al. (2017a).

\subsubsection{Central bending moment}

Similarly to the central axial compressive forces, this section presented the elastic bending moment at the crown of arches developed at constant span length $(L)$ of $500 \mathrm{~mm}$, and those developed at constant slender ratios $\left(S / r_{x}\right)$ of 60 and 90 . 
International Journal of Engineering Research and Technology. ISSN 0974-3154, Volume 13, Number 10 (2020), pp. 2870-2883

(C) International Research Publication House. https://dx.doi.org/10.37624/IJERT/13.10.2020.2870-2883

3.2.2.1 Bending moments of arches developed at constant span length moment at the crown $\left(4 M_{C} / F L\right)$ against the included angles $2 \alpha$ for arches developed at the constant span length $L=500 \mathrm{~mm}$.

Figure 9 presents the variation of the dimensionless bending

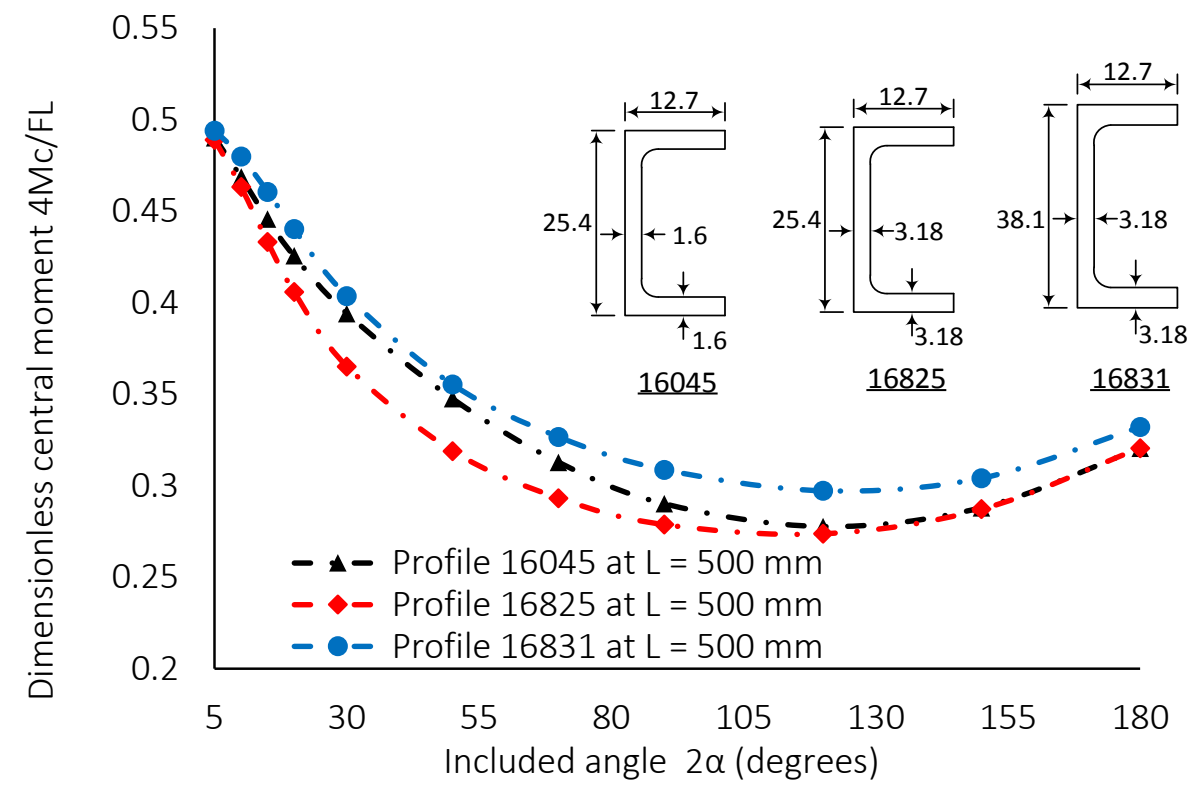

Figure 9: Cross-sections variations of the central bending moment with included angles

From Figure 9, it can be seen that for all the profiles, the $4 M_{C} / F L$ values first decreased to their minimum and then increased slightly with increase in the included angle. With an overall high $4 M_{C} / F L$ values for profile 16831 , one should expect the profile to have more resistance to LTB, followed by profile 16045 and then 16825. This expectation, however, should be more valid for arches developed at the constant slender ratios as reported in Liu et al. (2017a) research work. That said, the overall high $4 M_{C} / F L$ magnitude for profile 16831 was as a result of the close proximity between the positions of centroid and shear centre of the profile, followed by profiles 16045 and 16825, respectively with larger distances between their centroid positions and shear centres.

From reported studies, (Liu et al. 2017a), a general decrease in the bending moment increases the LTB load. However, the included angle at which the peak or least bending moment occur cannot be associated to the included angle at which the minimum or maximum LTB loads will occur. Table 5 summarized the different maximum and minimum $4 M_{C} / F L$ values in Figure 9 along their respective included angles and percentage difference. Similarly, profile 16825 was used as the reference to determine the impact of the web-flange thickness and web height on the bending moment.

Table 5: Maximum and minimum $4 M_{C} / F L$ values at the respective included angles and percentage difference for arches developed at constant span length

\begin{tabular}{|c|c|c|c|c|c|c|c|}
\hline \multicolumn{3}{|c|}{$\begin{array}{l}\text { Profile description } \\
\text { (dimensions in } \mathrm{mm} \text { ) }\end{array}$} & \multicolumn{2}{|c|}{$\begin{array}{l}\text { Maximum } 4 M_{C} / F L \\
\text { and corresponding } \\
\text { included angle } 2 \alpha\end{array}$} & \multicolumn{2}{|c|}{$\begin{array}{c}\text { Minimum } 4 M_{C} / F L \text { and } \\
\text { corresponding included } \\
\text { angle } 2 \alpha\end{array}$} & \multirow{2}{*}{$\begin{array}{c}\text { Minimum } 4 M_{C} / F L \\
\text { percentage difference at } \\
\text { corresponding included angle } \\
2 \alpha(\%) \text { Reference. } 16825\end{array}$} \\
\hline Profile & $\begin{array}{l}\text { Web \& flange } \\
\text { thickness }\end{array}$ & Web height & $4 M_{C} / F L$ & $2 \alpha\left(^{\circ}\right)$ & $4 M_{C} / F L$ & $2 \alpha\left(^{\circ}\right)$ & \\
\hline 16825 & 3.18 & 25.4 & 0.489 & 5 & 0.274 & 120 & - \\
\hline 16045 & 1.6 & 25.4 & 0.49 & 5 & 0.278 & 120 & 6.8 \\
\hline 16831 & 3.18 & 38.1 & 0.494 & 5 & 0.297 & 120 & 8.2 \\
\hline
\end{tabular}


It can be seen in Table 5 that all the three profiles attained their maximum and minimum $4 M_{C} / F L$ values at $2 \alpha=5^{\circ}$ and $120^{\circ}$, respectively. These similarities implied that the position of the centroid from the shear centre had insignificant influence on the included angles at which the maximum and minimum $4 M_{C} / F L$ values occurred. Rather, the position of the centroid from the shear centre had a slight significant impact on the profiles bending moments' magnitudes. That is, as the profile web-flange thickness decreased by $50 \%$, that is from profile 16825 to 16045 , the maximum bending moment of profile 16825 increased by only $6.8 \%$. On the other hand, when the web height is increased by $66.7 \%$, that is from profile 16825 to
16831, the maximum bending moment from profile 16825 only increased by $8.2 \%$. Again, it was noticed that the change in web-flange thickness and web height influences the bending moments' magnitudes and not the general behaviour.

\subsubsection{Bending moment of arches developed at constant slender ratios}

The typical disparity of the dimensionless central bending moment $4 M_{C} / F L$ at slender ratios $S / r_{x}=60$ and 90 with included angles $2 \alpha$ are as shown in Figure 10.

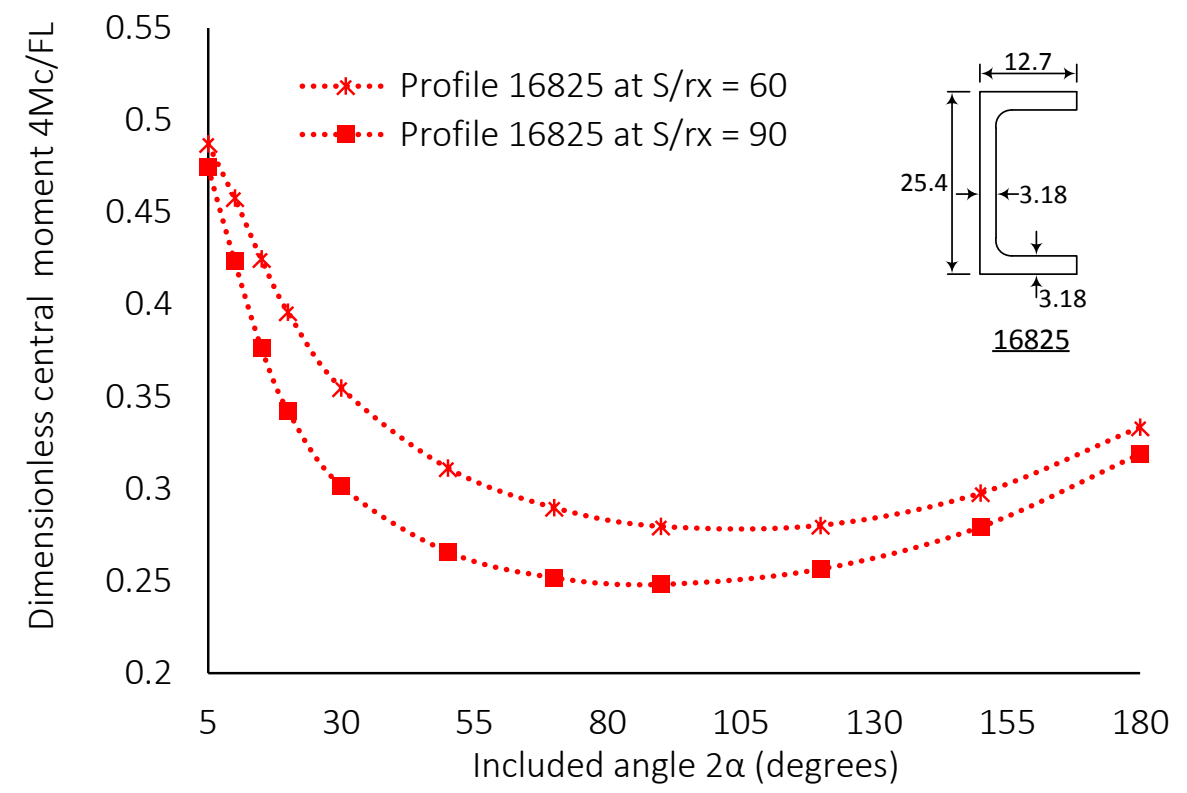

Figure 10: Slender ratios variations of the central bending moment with included angles

It was noted in Figure 10 that the $4 M_{C} / F L$ values for both slender ratios first decreased to their minimum values and then increased gradually with increase in the included angle. Also, an overall high $4 M_{C} / F L$ magnitude was observed for arches developed at $S / r_{x}=60$. The overall high magnitudes for these arches were due to the short arc length developed that render them less slender. Thus, highly resistive to bending as compared to arches with longer developed arc length at $S / r_{x}=$
90. For such arches with low slender ratios, one would expect more resistance to LTB as compared to those of higher slender ratios as observed by Liu et al. (2017a). Table 6 summarized the maximum and minimum $M_{C} / F L$ values at their respective included angles and percentage differences. The curve for arches developed at $S / r_{x}=60$ as shown in Figure 10, was used as the reference to determine the percentage difference due to their overall high $M_{C} / F L$ values.

Table 6: Maximum and minimum $4 M_{C} / F L$ values at their respective included angles and percentage difference for arches developed at constant slender ratios 60 and 90

\begin{tabular}{|c|c|c|c|c|c|}
\hline \multirow{2}{*}{$\begin{array}{l}\text { Slender } \\
\text { ratio } S / r_{x}\end{array}$} & \multicolumn{2}{|c|}{$\begin{array}{c}\text { Maximum } 4 M_{C} / F L \text { and } \\
\text { corresponding included angle } \\
2 \alpha\end{array}$} & \multicolumn{2}{|c|}{$\begin{array}{c}\text { Minimum } 4 M_{C} / F L \text { and } \\
\text { corresponding included angle } \\
2 \alpha\end{array}$} & \multirow{2}{*}{$\begin{array}{c}\text { Minimum } 4 M_{C} / F L \text { percentage difference at } \\
\text { corresponding included angle } 2 \alpha(\%), \\
\operatorname{Ref} S / r_{x}=60\end{array}$} \\
\hline & $4 M_{C} / F L$ & $2 \alpha\left(^{\circ}\right)$ & $4 M_{C} / F L$ & $2 \alpha\left(^{\circ}\right)$ & \\
\hline 60 & 0.487 & 5 & 0.28 & 90 & \multirow{2}{*}{11.9} \\
\hline 90 & 0.475 & 5 & 0.248 & 90 & \\
\hline
\end{tabular}

It can be seen in Table 6 that both slender ratios attained their maximum and minimum $4 M_{C} / F L$ values at $2 \alpha=5^{\circ}$ and $90^{\circ}$, resepctively. The similar included angles for both maximum and minimum $4 M_{C} / F L$ values, implied that the changed 
slender ratios did not influence the included angle at which the maximum or minimum $4 M_{C} / F L$ occurred. Rather, by increasing the slender ratio by $66.7 \%$, that is from 60 to 90 decreased the minimum $4 M_{C} / F L$ value by $11.9 \%$ at the relative included angle. This occurrence further confirms that the change in slender ratios only influences the bending moment magnitudes and not the general behaviour. This observation is in agreement to similar studies of Liu et al. (2017a) and Pi and Bradford (2003) on circular fixed arch arches subjected to point load.

\subsection{Elastic lateral-torsional buckling load and behaviour}

This section evaluates the effects of the change in web-flange thickness, web height, slender ratios and included angles on the
LTB loads and behaviour. Arches developed at $L=500 \mathrm{~mm}$ were used to evaluate the change web-flange thickness and web height coupled with the included angle. While arches developed at $S / r_{x}=60$ and 90 were used to evaluate the slender ratio effect coupled with the included angles.

\subsubsection{Effects of change in cross-sections on elastic lateral-torsional buckling loads of arches developed at constant span length}

The elastic LTB loads $\left(F_{c r}\right)$ are plotted against the respective included angles $(2 \alpha)$ as shown in Figure 11 for arches developed at $L=500 \mathrm{~mm}$. The change in web-flange thickness was represented by profile 16825 and 16045, while profiles 16825 and 16831 represented the change in web height.

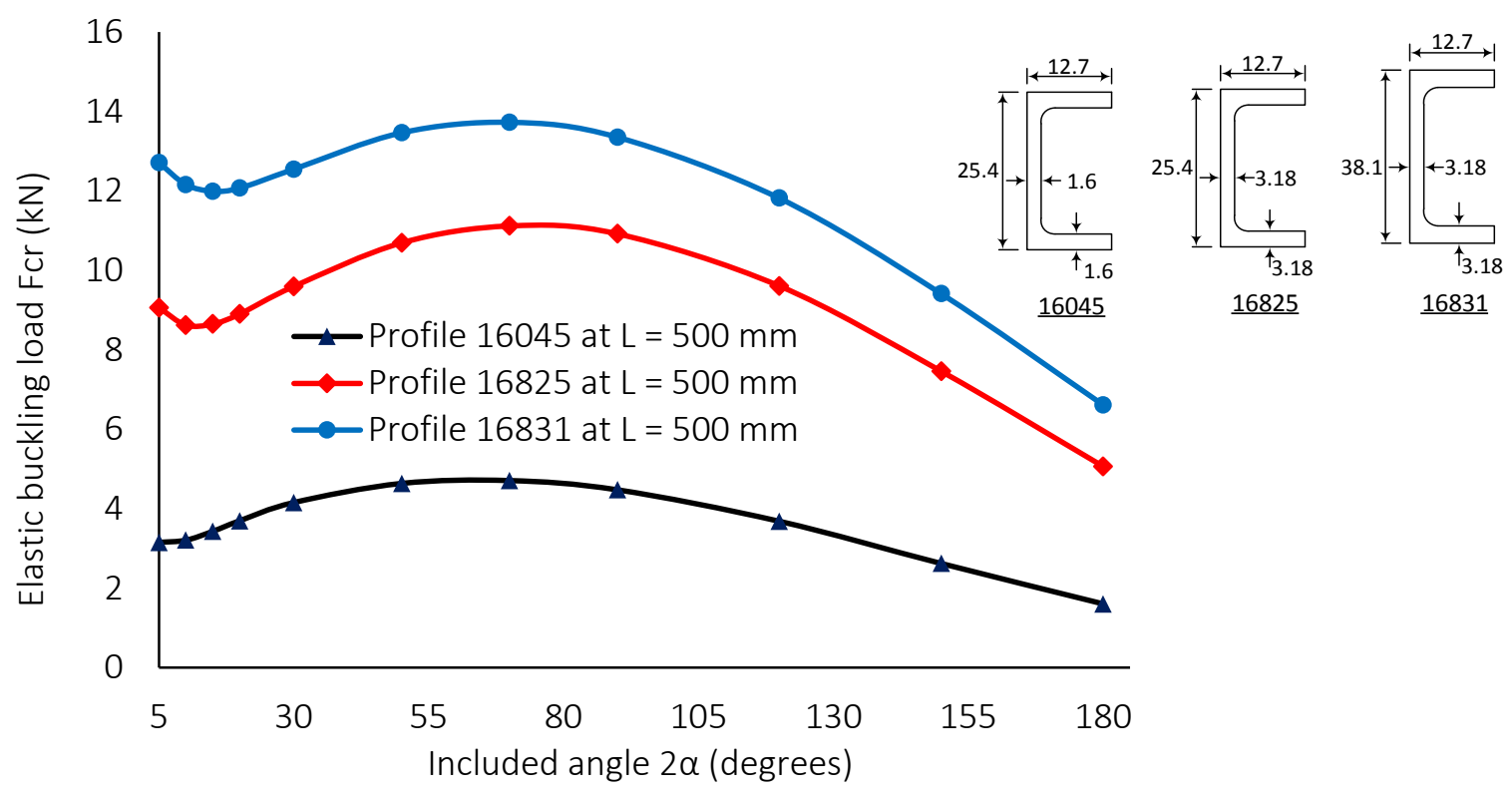

Figure 11: Effects of cross-section on the elastic lateral-torsional buckling load for fixed arches

It was observed in Figure 11 that as the included angles increased, the $F_{c r}$ values given by profiles 16825 and 16831 first decreased slightly to some values and then increased to a maximum value before decreasing to their minima at $2 \alpha=$ $180^{\circ}$. For profile 16045 , the magnitude of $F_{c r}$ first increased before decreasing gradually with increasing included angle. This behaviour can be related to the combined actions of the axial compressive forces and bending moments, where an increase in axial compressive force causes a decrease in the elastic LTB load. Whereas, a decrease in the bending moment causes an increase in the elastic LTB load.
Also, it was revealed from Figure 11 that profile 16831 has an overall high LTB load-carrying capacity followed by profiles 16825 and 16045 , respectively. These overall magnitudes are associated with the profiles torsion constant with profile 16831 having the highest value as outlined in Hulamin Extrusions, (2015). Scrutinizing the effects of the change in web-flange thickness and web height, Table 7 summarized the maximum and minimum $F_{c r}$ values at their respective included angles and the percentage differences. That said, it is worthy to note that the curve of profile 16825 shown in Figure 11 was used as the point of reference to determine the difference in percentages. 
International Journal of Engineering Research and Technology. ISSN 0974-3154, Volume 13, Number 10 (2020), pp. 2870-2883

(C) International Research Publication House. https://dx.doi.org/10.37624/IJERT/13.10.2020.2870-2883

Table 7: Maximum and minimum $F_{c r}$ values at their respective included angles and percentage difference for arches developed at constant span length

\begin{tabular}{|c|c|c|c|c|c|c|c|c|c|}
\hline \multicolumn{3}{|c|}{$\begin{array}{l}\text { Profile description } \\
\text { (dimensions in } \mathrm{mm} \text { ) }\end{array}$} & \multicolumn{2}{|c|}{$\begin{array}{c}\text { Maximum } F_{c r} \text { and } \\
\text { relative included } \\
\text { angle } 2 \alpha\end{array}$} & \multicolumn{2}{|c|}{$\begin{array}{c}\text { Minimum } F_{c r} \text { and } \\
\text { relative included } \\
\text { angle } 2 \alpha\end{array}$} & \multirow{2}{*}{$\begin{array}{c}\text { Maximum } F_{c r} \\
\text { percentage } \\
\text { difference at relative } \\
\text { included angle } 2 \alpha \text { in } \\
(\%) \text { Ref. } 16825\end{array}$} & \multicolumn{2}{|c|}{$\begin{array}{c}\text { Maximum } \\
\text { percentage } \\
\text { difference and } \\
\text { relative included } \\
\text { angle } 2 \alpha \text { Ref. } 16825\end{array}$} \\
\hline Profile & $\begin{array}{l}\text { Web \& flange } \\
\text { thickness }\end{array}$ & Web height & $F_{c r}$ in $\mathrm{kN}$ & $\begin{array}{l}2 \alpha \text { in } \\
\left({ }^{\circ}\right)\end{array}$ & $F_{c r}$ in $\mathrm{kN}$ & $\begin{array}{l}2 \alpha \text { in } \\
\left({ }^{\circ}\right)\end{array}$ & & $2 \alpha$ in $\left(^{\circ}\right)$ & $\%$ \\
\hline 16825 & 3.18 & 25.4 & 11.116 & 70 & 5.069 & 180 & - & - & - \\
\hline 16045 & 1.6 & 25.4 & 4.709 & 70 & 1.605 & 180 & 81 & 180 & 103.8 \\
\hline 16831 & 3.18 & 38.1 & 13.728 & 70 & 6.615 & 180 & 21 & 10 & 34.1 \\
\hline
\end{tabular}

From Table 7 , if the web height is increased by $66.8 \%$, that is from profile 16825 to 16831 the maximum LTB load rose by $21 \%$ for the same included angle. For the same profiles (16825 and 16831), the maximum increase in LTB load at the corresponding included angle was $34.1 \%$. On the other hand, if the web-flange thickness is decreased by $50 \%$ that is from profile 16825 to 16045 , the LTB load dropped by $81 \%$. Nevertheless, the maximum drop in the LTB loads rose up to $103.8 \%$ for the same angle. Additionally, it was revealed that the channel arches developed at constant span length would have their highest resistance to LTB at $2 \alpha=70^{\circ}$. While the least resistance to LTB would be produced by arches developed at $2 \alpha=180^{\circ}$. In summary, the change in cross-section dimension property significantly influenced the magnitudes of the LTB loads and not the overall behaviour across the included angles.

\subsubsection{Effects of change in slender ratios on elastic lateral- torsional buckling loads of arches developed at the constant slender ratios}

By use of profiles 16825, the effects of the slender ratios $S / r_{x}=60$ and 90 on the elastic critical buckling load $\left(F_{c r}\right)$ at included angles $(2 \alpha)$ are presented in Figure 12.

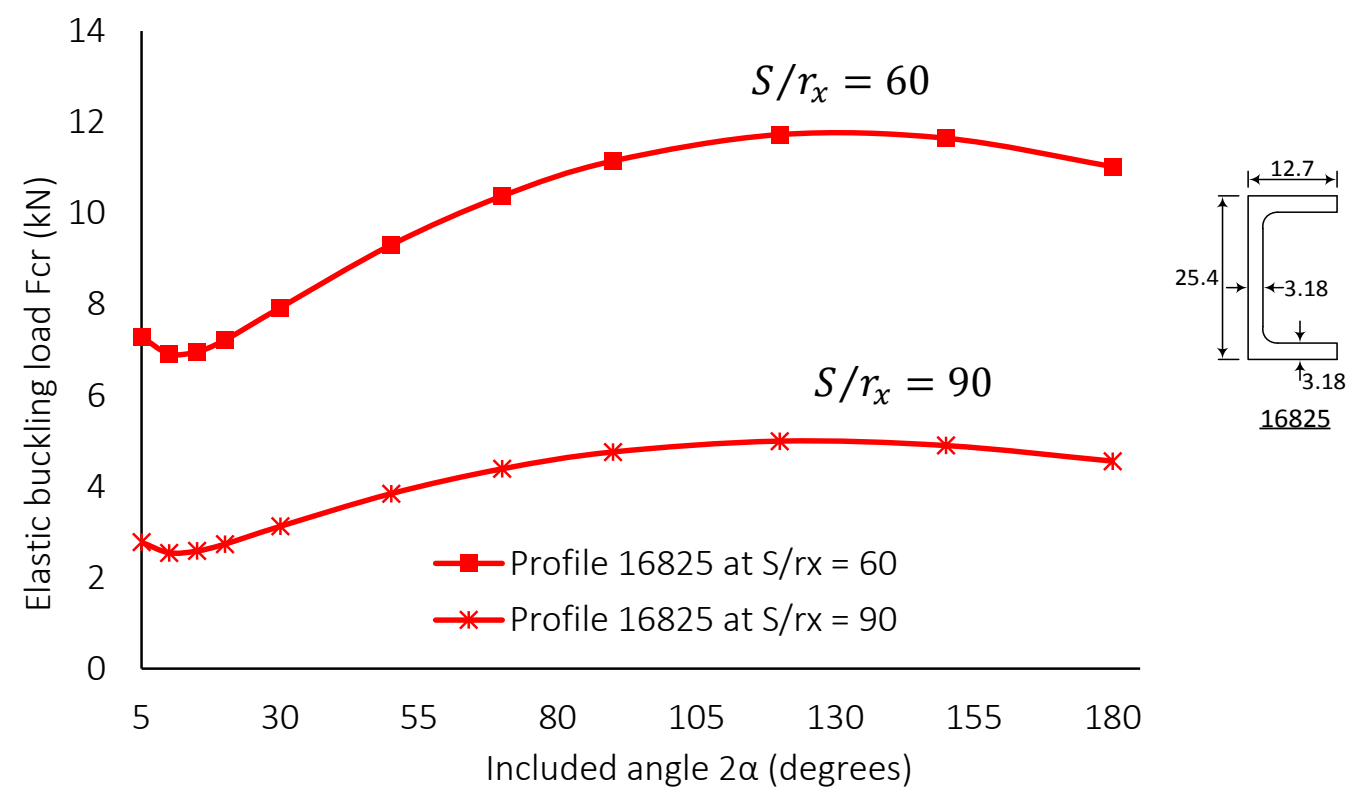

Figure 12: Slender ratios effects on the elastic lateral-torsional buckling load for fixed arches

It can be seen from Figure 12 that as the included angle increased continuously, the elastic LTB load $\left(F_{c r}\right)$ for both slender ratios first decreased slightly to their minima, then increased to their maxima, before they slightly decreased again.
The $F_{c r}$ magnitudes and behaviours were related to those of the axial compressive forces and bending moments discussed in section 3.2. As expected, the arches developed at $S / r_{x}=60$ with overall low elastic axial compressive forces and the high 
overall bending moment turned to have the highest LTB loads. The maximum and minimum $F_{c r}$ values at the corresponding included angles are summarized in Table 8. It is important to note that the curve developed at $S / r_{x}=60$ was used as the point of reference to determine the difference in percentage due to their overall high $F_{c r}$ magnitudes.

Table 8: Maximum and minimum $F_{c r}$ values at the respective included angles and percentage difference of arches developed at constant span length

\begin{tabular}{|c|c|c|c|c|c|c|c|}
\hline \multirow[t]{2}{*}{$\begin{array}{c}\text { Slender } \\
\text { ratios } \\
\left(S / r_{x}\right)\end{array}$} & \multicolumn{2}{|c|}{$\begin{array}{l}\text { Maximum } F_{c r} \text { and } \\
\text { relative included angle } 2 \alpha\end{array}$} & \multicolumn{2}{|c|}{$\begin{array}{l}\text { Minimum } F_{c r} \text { and } \\
\text { relative included angle } \\
2 \alpha\end{array}$} & \multirow{2}{*}{$\begin{array}{c}\text { Maximum } F_{c r} \\
\text { percentage } \\
\text { difference at relative } \\
\text { included angle } 2 \alpha \text { in } \\
\text { (\%) Ref. } S / r_{x}=60\end{array}$} & \multicolumn{2}{|c|}{$\begin{array}{c}\text { Maximum percentage } \\
\text { difference and relative included } \\
\text { angle } 2 \alpha \text { Ref. } S / r_{x}=60\end{array}$} \\
\hline & $F_{c r}$ in $\mathrm{kN}$ & $2 \alpha$ in $\left(^{\circ}\right)$ & $F_{c r}$ in $\mathrm{kN}$ & $2 \alpha$ in $\left(^{\circ}\right)$ & & $2 \alpha$ in $\left(^{\circ}\right)$ & $\%$ \\
\hline 60 & 11.731 & 120 & 6.915 & 10 & - & - & - \\
\hline 90 & 4.999 & 120 & 2.548 & 10 & 80.5 & 10 & 92.3 \\
\hline
\end{tabular}

As illustrated in Table 8 , if the slender ratio is increased by $66.7 \%$, that is from 60 to 90 the maximum LTB load dropped by $80.5 \%$ for the same included angle. However, for the same increase of the slender ratio, one should expect up to $92.3 \%$ drop of the LTB load at included angle $2 \alpha=10^{\circ}$. These occurrence is due to the high bending stresses on the compressive flange edge on shallow arches. Furthermore, it was revealed that for arches developed at constant slender ratios, the $120^{\circ}$ included angle would be more suitable for application in the area of high LTB due to the maximum LTB load noted at the included angle. On the other hand, the $10^{\circ}$ included angle would provide the least resistance to LTB. In summary, the change in the slender ratio significantly influences the LTB magnitudes and not the overall behaviour across the included angles. This occurrence reaffimed previous findings reported by Liu et al. (2017a) study.

\section{CONCLUSION}

1. The good agreements between the FEA and analytical results shows the effectiveness, and accuracy of the FE models used in this study.

2. The effects of the change in web-flange thickness, web height, and slender ratios were found to have significant influence on the overall prebuckling magnitudes. While, the included angles had significant impact on both the magnitude and behaviour.

3. For arches formed at constant span length and slender ratio, the axial compressive forces first increased to their peaks before decreasing. Whereas, the bending moments first decreased to their minima and then increased slightly with increase in the included angle.

4. For arches developed at constant span length, the overall high axial compressive force was found relative to the high distance between the centroid position and the shear center, while the low bending moments was relative to high distance between the centroid position and the shear center. For arches developed at constant slender ratios, arches with the high constant slender raito were found to have overal high axial compressive forces and low bending moments, and vice versa.

5. The axial compressive and bending actions' magnitudes for arches developed at constant span length were found not to be relative to the LTB loads magnitudes but depended on the torsion constant. On the other hand, those obtained from arches developed at constant slender ratios were relative to both the LTB load magnitudes and behaviours.

6. For arches developed at constant span length, the higher the torsion constant the higher the arch resistance against LTB at relative included angles.

7. For arches developed at constant slender ratios, the lower the slender ratio, the higher the arch resistance against LTB and vice versa.

8. In terms of included angle stability, it was found that the $70^{\circ}$ and $180^{\circ}$ included angles provided the maximum and minimum resistance against LTB, respectively. In general, moderate arches $\left(50^{\circ} \leq\right.$ $2 \alpha \leq 90^{\circ}$ ) provided high resistance against LTB, followed by shallow $\left(2 \alpha<50^{\circ}\right)$ and deep arches $\left(90^{\circ}<2 \alpha \leq 180^{\circ}\right)$, respectively.

9. For arches developed at constant slender ratios, it was found that the $120^{\circ}$ and $10^{\circ}$ included angles were noted to offer the maximum and minimum resistance against LTB, respectively. In summary, deep arches $\left(90^{\circ}<2 \alpha \leq 180^{\circ}\right)$ offered high resistance against LTB, followed by moderate $\left(50^{\circ} \leq 2 \alpha \leq 90^{\circ}\right)$ and deep $\left(2 \alpha<50^{\circ}\right)$ arches, respectively.

\section{RECOMMENDATIONS}

1. Though the methods used to develop the finite element model was validated and showed good agreement to existing solutions, an experimental study 
should be carried out on the actual studied models to further supplement the results presented in this study.

2. A nonlinear investigation should be considered as this study focused on the elastic analyses that ignored the effect of imperfections such as material non-linearity, inertial geometric imperfections, and residual stresses that may have significant impact on the LTB load.

3. Lastly, since the investigated arches are of structural 6061-T6 aluminium, similar studies should be conducted on different materials to understand better the elastic LTB load behavior at included angles.

\section{GLOSSARY}

LTB: Lateral-torsional buckling; FEA: Finite element analysis; Al: Aluminium; 3D: Three-dimensional; CAE: Computeraided engineering.

\section{ACKNOWLEDGMENT}

The Vaal University of Technology supports this research work. The authors want to thank the Department of Mechanical Engineering at the Vaal University of Technology for facilitating this work.

\section{FUNDING}

This research was funded by the NRF Block grant under the guidance of the Vaal University of Technology.

\section{AVAILABILITY OF DATA AND MATERIAL}

All cited articles in this review article are available upon request.

\section{AUTHORS' CONTRIBUTIONS}

All authors jointly contributed to the development of this journal article.

\section{COMPETING INTERESTS}

The authors declare that they have no competing interests.

\section{REFERENCE}

[1] Bajer, M., Barnat, J., \& Pijak, J. (2017). Lateral Torsional Buckling of Selected Cross-Section Types. Procedia Engineering, 190, 106-110. https://doi.org/10.1016/j.proeng.2017.05.314

[2] Dahmani, L., \& Drizi, S. (2015). Lateral torsional buckling of an eccentrically loaded channel section beam. Strength of Materials, 47(6), 912-916. https://doi.org/10.1007/s11223-015-9728-X

[3] Efthymiou, E., Cöcen, O. N., \& Ermolli, S. R. (2010). Sustainable aluminium systems. Sustainability, 2(9), 3100-3109. https://doi.org/10.3390/su2093100
[4] Hulamin Extrusions. (2015). Standard Profile Catalogue.

[5] Kim, M.-Y., Min, B.-C., \& Suh, M.-W. (2000). Spatial stability of nonsymmetric thin-walled curved beams. I: Analytical approach. Journal of Engineering Mechanics, 126(5), 497-505.

[6] La Poutré, D. B. (2005). Inelastic spatial stability of circular wide flange steel arches (Issue 2005). https://doi.org/10.6100/IR585818

[7] Liu, A., Lu, H., Fu, J., \& Pi, Y. L. (2017). Lateraltorsional buckling of fixed circular arches having a thin-walled section under a central concentrated load. Thin-Walled Structures, 118(May), 46-55. https://doi.org/10.1016/j.tws.2017.05.002

[8] Mazzolani, F. M. (2004). Design of Aluminium Structures.

[9] Metals, A. A. S. (2012). Aluminium 6061-T6; 6061T651. ASM Material Data Sheet, 7-8.

[10] Ozbasaran, H., Aydin, R., \& Dogan, M. (2015). An alternative design procedure for lateral-torsional buckling of cantilever I-beams. Thin-Walled Structures, 90, 235-242. https://doi.org/10.1016/j.tws.2015.01.021

[11] Pi, Y. L., Bradford, M. A., \& Tong, G. S. (2010). Elastic lateral-torsional buckling of circular arches subjected to a central concentrated load. International Journal of Mechanical Sciences, 52(6), 847-862. https://doi.org/10.1016/j.ijmecsci.2010.02.003

[12] Pi, Yong Lin, \& Bradford, M. A. (2003). Elastoplastic buckling and postbuckling of arches subjected to a central load. Computers and Structures, 81(1819), 1811-1825. https://doi.org/10.1016/S00457949(03)00204-9

[13] Pi, Yong Lin, \& Bradford, M. A. (2012). Non-linear in-plane analysis and buckling of pinned-fixed shallow arches subjected to a central concentrated load. International Journal of Non-Linear Mechanics, 47(4),

$118-131$ https://doi.org/10.1016/j.ijnonlinmec.2012.04.006

[14] Pi, Yong Lin, Bradford, M. A., \& Uy, B. (2005). A spatially curved-beam element with warping and Wagner effects. International Journal for Numerical Methods in Engineering, 63(9), 1342-1369. https://doi.org/10.1002/nme.1337

[15] Pi, Yong Lin, \& Trahair, N. S. (1996). Threedimensional nonlinear analysis of elastic arches. Engineering Structures, 18(1), 49-63. https://doi.org/10.1016/0141-0296(95)00039-3

[16] Pi, Yong Lin, \& Trahair, N. S. (2000). Inelastic lateral buckling strength and design of steel arches. Engineering Structures, 22(8), 993-1005. https://doi.org/10.1016/S0141-0296(99)00032-2

[17] Spoorenberg, R. C. (2011). Structural properties and out-of-plane stability of roller bent steel arches. https://doi.org/10.6100/IR716581

[18] Spoorenberg, R. C., Snijder, H. H., Hoenderkamp, J. C. D., \& Beg, D. (2012). Design rules for out-of-plane stability of roller bent steel arches with FEM. Journal of Constructional Steel Research, 79, 9-21. https://doi.org/10.1016/j.jcsr.2012.07.027 
International Journal of Engineering Research and Technology. ISSN 0974-3154, Volume 13, Number 10 (2020), pp. 2870-2883

(C) International Research Publication House. https://dx.doi.org/10.37624/IJERT/13.10.2020.2870-2883

[19] Tebo, E. T., Masu, L., \& Nziu, P. (2020). Effects of Factors That Influence Out-of-Plane LateralTorsional Buckling on Freestanding Circular Arches. Journal of Engineering, 2020, 1-12. https://doi.org/10.1155/2020/4892070

[20] Valeš, J., \& Stan, T. (2017). FEM Modelling of Lateral-Torsional Buckling using Shell and Solid Elements. 190, 464-471. https://doi.org/10.1016/j.proeng.2017.05.365

[21] Wang, Y. Q., Yuan, H. X., Shi, Y. J., \& Cheng, M. (2012). Lateral-torsional buckling resistance of aluminium I-beams. Thin-Walled Structures, 50(1), 24-36. https://doi.org/10.1016/j.tws.2011.07.005

[22] Wesley, D. (2017). Lateral-torsional Buckling of Steel Channel Beams A parametric study through FEanalysis.

[23] Yang, Y., Kuo, S., \& Cherng, Y. (1989). Curved Beam Elements for Nonlinear Analysis. Journal of Engineering Mechanics, 115(4), 840-855. https://doi.org/10.1061/(ASCE)07339399(1989)115:4(840) 